\title{
Evaluation of outcome of pregnancy complicated by intrahepatic cholestasis of pregnancy
}

\author{
Abha Rani Sinha ${ }^{1}$, Sneh Kiran ${ }^{2 *}$ \\ ${ }^{1}$ Department of Obstetrics and Gynecology, Patna Medical College and Hospital, Patna, Bihar, India \\ ${ }^{2}$ Department of Obstetrics and Gynecology, Indira Gandhi Institute of Medical Sciences, Patna, Bihar, India
}

Received: 01 April 2018

Accepted: 30 April 2018

*Correspondence:

Dr. Sneh Kiran,

E-mail: drsnehkiran@gmail.com

Copyright: ( $)$ the author(s), publisher and licensee Medip Academy. This is an open-access article distributed under the terms of the Creative Commons Attribution Non-Commercial License, which permits unrestricted non-commercial use, distribution, and reproduction in any medium, provided the original work is properly cited.

\begin{abstract}
Background: Obstetric cholestasis (OC), also known as intrahepatic cholestasis of pregnancy (ICP), is a hepatic disease unique to pregnancy which presents with intense generalized pruritus without any skin rash. The aim is to study the outcome of pregnancy both maternal and fetal complicated by OC.

Methods: This retrospective case control study was conducted at the Department of Obstetrics and Gynecology, Patna Medical College and Hospital, Patna. The medical records of all women with OC who delivered between Jan 2015 and Jan 2016 were reviewed.

Results: The incidence of OC was $8.2 \%$. The most common symptom was generalized pruritus which appeared after 28 weeks in $73.3 \%$ cases. The cesarean section rate was $93.3 \%$. A higher incidence of meconium staining in amniotic fluid at delivery $(17.1 \%$ vs $1.1 \%, \mathrm{p}<0.005)$ and preterm premature rupture of membranes $(8.9 \%$ vs $1.1 \%$, p <0.01) was noted without an increase in preterm delivery rate $(24.4 \%$ vs $15.6 \%)$. There was no statistically significant difference in the following parameter - pathological cardiotocography, 1-5 minuteApgar score <7, intrauterine growth restriction, neonatal intensive care admission or perinatal mortality. There was no case of postpartum hemorrhage.

Conclusions: The incidence of OC is high in the Indian population. Perinatal outcome is good in actively managed women, although at the cost of a high intervention rate.
\end{abstract}

Keywords: Intrahepatic cholestasis, Obstetric cholestasis, Perinatal outcome

\section{INTRODUCTION}

Obstetric cholestasis (OC), also known as intrahepatic cholestasis of pregnancy is a hepatic disease unique to pregnancy which presents with intense generalized pruritus without any skin rash. ${ }^{1}$ It is a temporary condition caused by maternal liver dysfunction during pregnancy and blood tests reveal increased levels of one or more of the liver enzymes. ${ }^{2}$

The pathophysiology of intrahepatic cholestasis is poorly understood. ${ }^{3}$ Alternative causes of itching and abnormal liver function tests (LFTs) should be excluded. ${ }^{1,2}$
Postnatal resolution of pruritus and abnormal LFTs should be confirmed to establish the diagnosis. ${ }^{2}$ Prevalence in women of Indian Origin is $5 \% .^{2}$ The prevalence may have seasonal cycles and may be more prevalent in winters. The importance of OC lies in the associated adverse pregnancy outcome.

The potential risks are intrauterine fetal death, prematurity (usually iatrogenic), fetal distress and postpartum hemorrhage (PPH). ${ }^{3-6}$ It is also associated with significant maternal morbidity due to persistent itching and consequent sleep deprivation. ${ }^{2}$ Present study was aimed at determining the incidence of $\mathrm{OC}$ in our 
hospital, studying the course of pregnancy and evaluating the pregnancy outcome in these women.

\section{METHODS}

This retrospective case control study was conducted at the Department of Obstetrics and Gynecology, Patna Medical College and Hospital, Patna. The medical records of all women with $\mathrm{OC}$ who delivered between Jan 2015 and Jan 2016 were reviewed. Two women were chosen as control for each case of OC; the women delivering immediately before and after each case of OC were chosen as control. From the case records the patient profile, complaints, associated medical and obstetric complications were noted. The records of investigations, treatment and the pregnancy outcome were studied. The diagnosis of OC was secured on the basis of the symptom of persistent generalized pruritus, biochemical evidence of altered LFTs and the remission of both following delivery. Pregnancy specific ranges of LFTs were used. For the transaminases, gamma glutamyl transferase (GGT) and bilirubin in pregnancy, the upper limit of normal value is $20 \%$ lower than that in the nonpregnant state. Other causes of altered LFTs were excluded by hepatitis serology, hepatobiliary sonography and liver autoimmune screen (for primary biliary cirrhosis) wherever indicated. The monitoring of women with OC included regular prenatal visits with LFTs every 10-14 days. Fetal surveillance was done with daily maternal recording of fetal movements, regular sonography including amniotic fluid index (every 7-14 days depending on the period of gestation) and twice weekly nonstress test (NST) beginning at 34 weeks of gestation. Control group had regular prenatal visits and NST when indicated by obstetric conditions. We noted the occurrence of complications of pregnancy including preterm premature rupture of membranes (PPROM) and preterm delivery.

Authors also noted the mode of delivery, the cardiotocographic findings during fetal surveillance, the presence of meconium during delivery, Apgar score at 1 and 5 minutes, intrauterine growth restriction (IUGR), need for neonatal intensive care (NICU) admission and perinatal mortality.

\section{Statistical analysis}

Statistical analysis was performed using the $\mathrm{z}$ test when appropriate. A p value $<0.05$ was considered statistically significant.

\section{RESULTS}

During the study period 5500 deliveries were performed at our institution. Of these women, 450(8.2\%) were diagnosed with OC. The mean age of these women was 28.7 years (20-37 years). 310 were nulliparous and of the 140 parous women. Ninty $(64.3 \%)$ had a previous history of cholestasis. Women in the study group and the control group were similar in age and parity (Table 1).

Table 1: Comparison between cases and controls regarding maternal profile, pregnancy outcome and fetal outcome.

\begin{tabular}{|c|c|c|c|}
\hline & $\begin{array}{l}\text { Cholestasis } \\
\text { of pregnancy } \\
(n=450)\end{array}$ & $\begin{array}{l}\text { Control } \\
(\mathrm{n}=900)\end{array}$ & $\begin{array}{l}\text { p value } \\
<0.01\end{array}$ \\
\hline Mean age (Range) & $\begin{array}{l}28.7 \mathrm{yrs} \\
(20-37)\end{array}$ & $\begin{array}{l}28.5 \mathrm{yrs} \\
(18-40)\end{array}$ & \\
\hline Primiparous (\%) & 68.9 & 68.2 & \\
\hline Multiparous (\%) & 31.1 & 31.8 & \\
\hline $\begin{array}{l}\text { Preterm premature } \\
\text { rupture } \\
\text { of membranes }\end{array}$ & $40 / 450(8.9)$ & $\begin{array}{l}10 / 900 \\
(1.1)\end{array}$ & \\
\hline Preterm delivery & $\begin{array}{l}100 / 450 \\
(24.4)\end{array}$ & $\begin{array}{l}140 / 900 \\
(15.6)\end{array}$ & $>0.05$ \\
\hline $\begin{array}{l}\text { Total cesarean } \\
\text { section }\end{array}$ & $\begin{array}{l}420 / 450 \\
(93.3)\end{array}$ & $\begin{array}{l}690 / 900 \\
(76.7)\end{array}$ & $>0.05$ \\
\hline $\begin{array}{l}\text { Postpartum } \\
\text { hemorrhage }\end{array}$ & 0 & 0 & \\
\hline $\begin{array}{l}\text { Meconium } \\
\text { staining of } \\
\text { amniotic fluid }\end{array}$ & $\begin{array}{l}80 / 450 \\
(17.8)\end{array}$ & $\begin{array}{l}10 / 900 \\
(1.1)\end{array}$ & $<0.005$ \\
\hline $\begin{array}{l}\text { Abnormal } \\
\text { cardiotocography }\end{array}$ & $20 / 450(4.4)$ & $\begin{array}{l}50 / 900 \\
(5.6)\end{array}$ & $>0.05$ \\
\hline $\begin{array}{l}\text { Apgar }<7 \text { at } 5 \\
\text { mins }\end{array}$ & $20 / 450(4.4)$ & $\begin{array}{l}20 / 900 \\
(2.2)\end{array}$ & $>0.05$ \\
\hline $\begin{array}{l}\text { Intrauterine } \\
\text { growth restriction }\end{array}$ & $40 / 450(8.9)$ & $\begin{array}{l}70 / 900 \\
(7.8)\end{array}$ & $>0.05$ \\
\hline $\begin{array}{l}\text { Neonatal intensive } \\
\text { care admissions }\end{array}$ & $\begin{array}{l}70 / 450 \\
(15.6)\end{array}$ & $\begin{array}{l}140 / 900 \\
(15.6)\end{array}$ & $>0.05$ \\
\hline Perinatal deaths & 10 & 60 & \\
\hline $\begin{array}{l}\text { Perinatal mortality } \\
\text { rate (per } 1000 \text { live } \\
\text { births) }\end{array}$ & $22.7 \%$ & $69.7 \%$ & \\
\hline
\end{tabular}

Generalized pruritus worsening at night, causing variable degree of sleep deprivation was the principal symptom seen in all the women with cholestasis.

The palms and the soles were worst affected by the pruritus in $170 / 450(37.8 \%)$ women. Fifty women complained of dark colored urine $(11.1 \%)$. There was no case of clinical jaundice. In 330/450 (73.3\%) women the gestational age at diagnosis of OC was after 28 weeks with the maximum number being diagnosed between 32 36 weeks. In only $80 / 450(17.8 \%)$ women the symptom started before 20 weeks (Figure 1).

Using pregnancy specific ranges for the LFTs it was found that the most frequent abnormality encountered in OC was elevated transaminases $(97.8 \%)$ and GGT $(42.9 \%)$. The peak value of alanine aminotransferase (ALT), aspartate aminotransferase (AST) in present study ranged from 32-606 U/Land 46-634 U/L respectively.

The value of ALP in these women varied from normal to as high as $900 \mathrm{U} / \mathrm{L}$. Mild hyperbilirubinemia was present 
in $18.4 \%$ of the women and the highest bilirubin level noted was $2.3 \mathrm{mg} \%$.

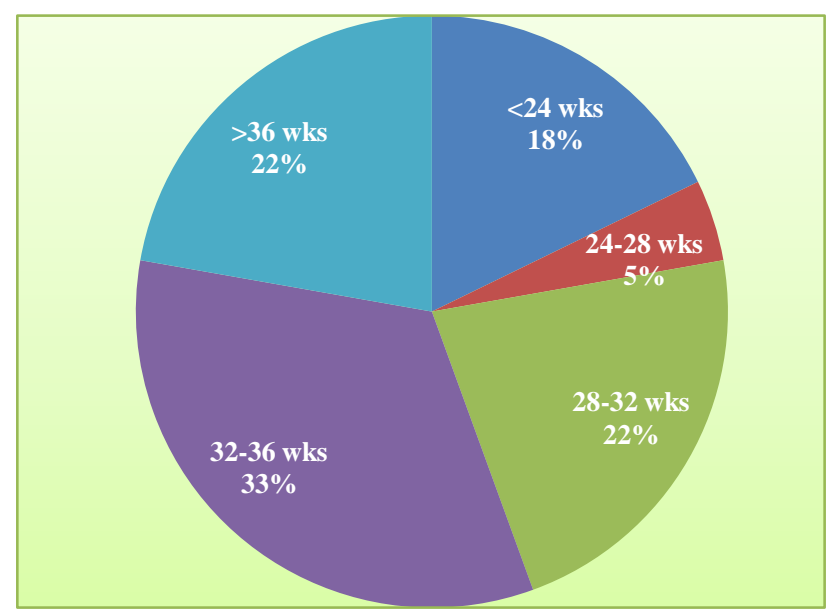

Figure 1: Gestational age at diagnosis in obstetric cholestasis.

Topical emollients and oral antihistaminics were offered to all the subjects for relief of pruritus. 90/450 women (20\%) had partial relief; 360/450 (80\%) women were given ursodeoxycholic acid (UDCA) in a dose of 600$1800 \mathrm{mg} /$ day. All the women reported partial or complete relief of pruritus and there was biochemical improvement in $340 / 360(94.4 \%)$ women. 190/450 (42.2\%) women were prescribed parental vitamin $K$. The incidence of PPROM was significantly higher in the study group compared to the control group ( $8.9 \%$ vs $1.1 \%, \mathrm{p}<0.05)$. The mean gestational age at delivery in the OC group ranged between 32-39 weeks with most of the women delivering at 37-38 weeks (Figure 2). Although the incidence of preterm delivery was higher in the study group $(24.4 \%$ vs $15.6 \%)$ this did not attain statistical significance ( $\mathrm{p}>0.05)$. The cesarean section $(\mathrm{CS})$ rate was higher in the study group (93.3\% vs $76.7 \%$ ), but even this did not attain statistical significance ( $p>0.05)$. The higher CS rate was mainly due to a higher elective CS (76.2\% vs $65.2 \%$ ). There was no case of PPH in either group (Table 1). Perinatal outcome is shown in Table 1.

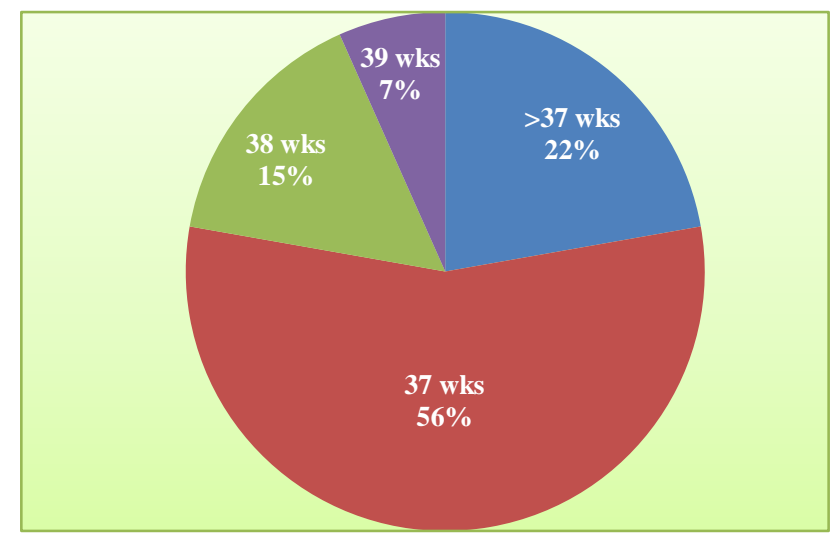

Figure 2: Gestational age at delivery in obstetric cholestasis.
In the OC group there was a higher incidence of meconium staining of amniotic fluid $(17.7 \%$ vs $1.1 \%$, $\mathrm{p}<0.005)$. There were no significant differences in the incidence of abnormal cardiotocography, Apgar score at 1 minute and 5 minutes, incidence of IUGR or NICU admissions. Perinatal mortality is shown in Table 1 . No significant differences were observed in the fetal, neonatal or perinatal mortality rates between the groups. 10 stillbirth and no neonatal deaths were observed in the OC group while in the control group there were forty stillbirths and twenty neonatal deaths.

\section{DISCUSSION}

The prevalence of $\mathrm{OC}$ is influenced by genetic and environmental factors and varies between populations. ${ }^{3}$ It is most common in Chile where $2.4 \%$ of all pregnancies are affected. ${ }^{2}$ The incidence of OC among Indian women has been reported as about 1\%.,7 Authors found an incidence of $8.2 \%$ in present study. However, it is prudent to mention that our hospital is a tertiary referral hospital and the incidence of high risk pregnancy is higher. Hence the incidence of $\mathrm{OC}$ is expected to be higher than that in the community. Some authors have reported that women of relatively advanced age ( $>35 \mathrm{yrs}$ ) are at increased risk of developing OCs but we found that the mean age was 28.7 years (range 20-37yrs) and there was no significant difference between the two groups in maternal age or parity.

OC tends to recur in subsequent pregnancies in up to 60$70 \%$ of the women. ${ }^{3}$ In the present study the recurrence rate was $64.3 \%$ among multiparous women. In $71.1 \%$ women, $\mathrm{OC}$ was diagnosed in the third trimester which is similar to that seen in other studies.,7 Generalized pruritus was the major symptom in all women and was more in the palms and soles in $37.8 \%$ women. We found no case of clinical jaundice. However, it has been reported in upto $10 \%$ women. ${ }^{5}$ Abnormalities in one or more of the transaminases, GGT, bilirubin and/or bile salts are consistent with a diagnosis of OC. The most commonly elevated LFTs have been reported as transaminases and total serum bile acid. ${ }^{2}$ In present study the transaminases were raised in $97.8 \%$ of the women and the maximum value encountered in present study was twenty times the normal value in pregnancy. Various studies have reported that elevated levels of GGT and bilirubin have been noted in upto $50 \%$ and $22-56 \%$ patients respectively but clinical jaundice is rare. ${ }^{1}$ In present study authors found raised levels of GGT in $42.9 \%$ patients and hyperbilirubinemia in $18.4 \%$ women. There was no case of jaundice. As bile salt assessment is not available we could not determine the levels in our patients. The efficacy of topical emollients like calamine lotion and oral antihistaminics like chlorpheniramine has not been tested in clinical trials but their use is safe in pregnancy and for some women may provide mild temporary relief of pruritus. $^{2}$ In present study $20 \%$ of the women reported partial relief. Several studies demonstrate that in addition to providing safe and 
effective relief of pruritus and improving LFTs, UDCA may improve the prenatal outcome by preventing the accumulation of biliary constituents of maternal origin in the fetus, which may contribute to the risk of fetal distress and even stillbirth. ${ }^{8,9}$ In present study UDCA was prescribed in $80 \%$ of the women and there was partial or complete relief of pruritus in all with biochemical improvement in $94.4 \%$ women. Kenyon et al found a high incidence of PPH in women with OC who did not receive vitamin $\mathrm{K}$ compared to those who did (45\% vs $12 \%$ ), but we found no case of PPH though only $42.2 \%$ of the women on present study received vitamin $K{ }^{4}$ The disease has been related to a high incidence of perinatal complications including an increase in perinatal mortality rate $(35 / 1000)$, a high incidence of meconium stained amniotic fluid (upto 45\%), preterm labor (upto 44\%), and fetal distress (upto 22\%). ${ }^{5,6}$ Present study shows a significant increase in the incidence of PPROM and meconium staining of amniotic fluid in the OC group. It has been suggested that both fetal distress and increased stimulation of colonic motility by bile acids is the cause of increased incidence of meconium staining on OC. ${ }^{6}$ Unlike other studies we did not find a significant increase in preterm deliveries, fetal distress, NICU admissions or perinatal mortality. No association with IUGR has been reported and in this study also we found no significant increase in growth restriction. ${ }^{4,5}$ Intrauterine fetal demise appears to be an acute anoxic event and the high concentrations of fetal bile acids may contribute to this acute event. The risk of fetal death increases near term and most deaths occur after 37-38 weeks. To avoid the risk many hospitals adopt a policy of active management with antenatal surveillance and early elective delivery at 37-38 weeks. $^{1}$ In present study active management including intensive fetal surveillance with delivery between 37-38 completed weeks of gestation was used. The only stillbirth in the OC group in present study was an unbooked woman who came in at 39 weeks gestation with the complaint of loss of fetal movements and ultrasonography on admission confirmed fetal demise. The mother did not have other complications of pregnancy and the fetus was grossly normal with appropriate weight for gestational age. Apart from the significant morbidity due to the intense pruritus, OC does not seem to have serious health consequences for the mother. There is an increased risk of delivery by CS (25.9-36\%) though it is not clear whether the high rates are due to active management or because of complications as a result of the disease or both. PPH has been observed in 2-25\% patients in some studies. ${ }^{4,5,7}$ In present study the CS rate of $93.3 \%$ was high but not significantly higher than that in the control group. The CS rate in our hospital is high in view of the higher incidence of complicated pregnancies.

\section{CONCLUSION}

Obstetric cholestasis occurs in the third trimester of pregnancy with pruritus as a cardinal symptom. It is associated with increased maternal morbidity and perinatal mortality and morbidity. Early diagnosis with careful clinical examination and biochemical testing is essential. Affected women should be offered treatment with UDCA. This provides symptomatic relief, improvement of liver function and may contribute to improvement in the perinatal outcome. Close monitoring in antenatal period and induction of labor at 37-38 weeks may improve perinatal outcome.

\section{Funding: No funding sources}

Conflict of interest: None declared

Ethical approval: The study was approved by the Institutional Ethics Committee

\section{REFERENCES}

1. Kenyon AP, Girling JC, Obstetric cholestasis. In, Studd J. (Editor), Progress in Obstetrics and Gynaecology Edinburgh: Churchill Livingstone, 2005;37-56.

2. Royal College of Obstetricians and Gynecologists. Obstetric cholestasis. RCOG Guideline No.43;2006.

3. Reyes H. The spectrum of liver and gastrointestinal disease seen in cholestasis of pregnancy. Gastroenterol Clin North Am. 1992;21:905-21.

4. Kenyon AP, Piercy CN, Girling J, Williamson C, Tribe RM, Shennan AH. Obstetric cholestasis, outcome with active management: a series of 70 cases. BJOG 2002;109:282-8.

5. Rioseco AJ, Ivankovic MB, Manzur A, Hamed F, Kato SR, Parer JT, et al. Intrahepatic cholestasis of pregnancy: a retrospective case-control study of perinatal outcome. Am J Obstet Gynecol 1994;170:8905.

6. Fisk NM, Storey GN. Fetal outcome in obstetric cholestasis. Br J Obstet Gynaecol. 1988;95:1137-43.

7. Ray A, Tata RJ, Balsara R. Cholestasis of pregnancy. $\mathbf{J}$ Obstet Gynecol India. 2005;55:247-50.

8. Zapata R, Sandoval L, Palma J. Ursodeoxycholic acid in the treatment of intrahepatic cholestasis of pregnancy. A 12-year experience. Liver Int. 2005;25:548-54.

9. Rodrigues CM, Marin JJ, Brites D. Bile acid patterns in meconium are influenced by cholestasis of pregnancy and not altered by ursodeoxycholic acid treatment. Gut. 1999;45:446-52.

Cite this article as: Sinha AR, Kiran S. Evaluation of outcome of pregnancy complicated by intrahepatic cholestasis of pregnancy. Int J Reprod Contracept Obstet Gynecol 2018;7:2360-3. 